\title{
Using single-case experimental design methodologyto evaluate the effects of the ABC method for nursing staff on verbal aggressive behaviour after acquired brain injury
}

Citation for published version (APA):

Winkens, I., Ponds, R., Pouwels, C., Eilander, H., \& van Heugten, C. M. (2014). Using single-case experimental design methodologyto evaluate the effects of the $\mathrm{ABC}$ method for nursing staff on verbal aggressive behaviour after acquired brain injury. Neuropsychological Rehabilitation, 24(3-4), 349-364. https://doi.org/10.1080/09602011.2014.901229

Document status and date:

Published: 01/01/2014

DOI:

10.1080/09602011.2014.901229

Document Version:

Publisher's PDF, also known as Version of record

Document license:

Taverne

Please check the document version of this publication:

- A submitted manuscript is the version of the article upon submission and before peer-review. There can be important differences between the submitted version and the official published version of record. People interested in the research are advised to contact the author for the final version of the publication, or visit the $\mathrm{DOI}$ to the publisher's website.

- The final author version and the galley proof are versions of the publication after peer review.

- The final published version features the final layout of the paper including the volume, issue and page numbers.

Link to publication

\footnotetext{
General rights rights.

- You may freely distribute the URL identifying the publication in the public portal. please follow below link for the End User Agreement:

www.umlib.nl/taverne-license

Take down policy

If you believe that this document breaches copyright please contact us at:

repository@maastrichtuniversity.nl

providing details and we will investigate your claim.
}

Copyright and moral rights for the publications made accessible in the public portal are retained by the authors and/or other copyright owners and it is a condition of accessing publications that users recognise and abide by the legal requirements associated with these

- Users may download and print one copy of any publication from the public portal for the purpose of private study or research.

- You may not further distribute the material or use it for any profit-making activity or commercial gain

If the publication is distributed under the terms of Article $25 \mathrm{fa}$ of the Dutch Copyright Act, indicated by the "Taverne" license above, 


\section{Using single-case experimental design methodology to evaluate the effects of the $A B C$ method for nursing staff on verbal aggressive behaviour after acquired brain injury}

leke Winkens, Rudolf Ponds, Climmy Pouwels, Henk Eilander \& Caroline van Heugten

To cite this article: leke Winkens, Rudolf Ponds, Climmy Pouwels, Henk Eilander \& Caroline van Heugten (2014) Using single-case experimental design methodology to evaluate the effects of the $A B C$ method for nursing staff on verbal aggressive behaviour after acquired brain injury, Neuropsychological Rehabilitation, 24:3-4, 349-364, DOI: 10.1080/09602011.2014.901229

To link to this article: https://doi.org/10.1080/09602011.2014.901229

Published online: 28 Apr 2014.

щ Article views: 699

View Crossmark data ¿
Submit your article to this journal $₫$
Q View related articles $₫$

Citing articles: 1 View citing articles $\longleftarrow$ 


\section{Using single-case experimental design methodology to evaluate the effects of the $\mathrm{ABC}$ method for nursing staff on verbal aggressive behaviour after acquired brain injury}

\section{Ieke Winkens ${ }^{1}$, Rudolf Ponds ${ }^{1,2}$, Climmy Pouwels ${ }^{3}$, Henk Eilander ${ }^{4}$, and Caroline van Heugten ${ }^{1,5}$}

${ }^{1}$ Department of Psychiatry and Neuropsychology, School for Mental Health and Neuroscience (MHeNS), Maastricht University, The Netherlands ${ }^{2}$ Adelante Rehabilitation Center, Hoensbroek, The Netherlands ${ }^{3}$ Department Huize Padua, GGZ Oost Brabant, Boekel, The Netherlands ${ }^{4}$ Department of Primary and Community Care, Radboud University Nijmegen, The Netherlands ${ }^{5}$ Department of Neuropsychology and Psychopharmacology, Faculty of Psychology and Neuroscience, Maastricht University, The Netherlands

(Received 1 July 2013; accepted 1 March 2014)

The $\mathrm{ABC}$ method is a basic and simplified form of behavioural modification therapy for use by nurses. ABC refers to the identification of Antecedent events, target Behaviours, and Consequent events. A single-case experimental $\mathrm{AB}$ design was used to evaluate the effects of the $\mathrm{ABC}$ method on a woman diagnosed with olivo-ponto-cerebellar ataxia. Target behaviour was verbal aggressive behaviour during ADL care, assessed at 9 time points immediately before implementation of the $\mathrm{ABC}$ method and at 36 time points after implementation. A randomisation test showed a significant treatment effect between the baseline and intervention phases $(t=.58, p=.03$; ES [Nonoverlap All Pairs] = .62). Visual analysis, however, showed that the target behaviour was still present after implementation of the method and that on some days

Correspondence should be addressed to Ieke Winkens, Maastricht University, School for Mental Health and Neuroscience, location DRT 12, P.O. Box 616, 6200 MD Maastricht, The Netherlands. E-mail: i.winkens@maastrichtuniversity.nl

Conflicts of interest: None declared. This work was supported by the Dutch National Initiative Brain and Cognition (NIBC). The project is embedded in the pillar 'The Healthy Brain, programme Cognitive Rehabilitation' [grant number 056-11-013]. 
the nurses even judged the behaviour to be more severe than at baseline. Although the target behaviour was still present after treatment, the $\mathrm{ABC}$ method seems to be a promising tool for decreasing problem behaviour in patients with acquired brain injury. It is worth investigating the effects of this method in future studies. When interpreting single-subject data, both visual inspection and statistical analysis are needed to determine whether treatment is effective and whether the effects lead to clinically desirable results.

Keywords: Single-case experimental design; Acquired brain injury; Aggressive behaviour; Behavioural modification therapy; ABC method.

\section{INTRODUCTION}

Behavioural and emotional problems are common consequences of acquired brain injury $(\mathrm{ABI})$ and they put a high burden on the patient, the patient's family and health care professionals (Alderman, 2007; Azouvi, Jokic, Attal, Deny, \& Bussel, 1999; Johnson \& Balleny, 1996; Kant, Smith-Seemiller, \& Zeiler, 1998).

One common and persisting behavioural consequence of $\mathrm{ABI}$ is aggressive behaviour. Studies on the prevalence of aggressive behaviour in patients with ABI resulting from causes other than traumatic brain injuries (such as for example stroke or hypoxia) are scarce, but aggressive behaviour is shown in approximately $25 \%$ of adults with moderate to severe traumatic brain injury at different stages of their illness (Baguley, Cooper, \& Felmingham, 2006; Ciurli, Formisano, Bivona, Cantagallo, \& Angelelli, 2011; Visscher, Van Meijel, Stolker, Wiersma, \& Nijman, 2011). Damage to frontal brain structures and to the connections between frontal brain structures and limbic structures is thought to be a major determinant of the disruptive behaviour in this patient group (Alderman, 2007). Verbal aggressive behaviour is most common (e.g., yelling, cursing), but physical aggression directed at other people (e.g., hitting) or objects (e.g., breaking things) can also occur (Alderman, Knight, \& Henman, 2002).

In the clinic, one way to manage behavioural problems is by means of behavioural modification therapy. There is a rich variety of behavioural modification therapy approaches available. A common approach is to use systematic and planned manipulations of triggers and consequences to increase the frequency of desirable behaviour and to decrease the frequency of undesirable behaviour (e.g., by eliminating provoking stimuli; see Ylvisaker et al., 2007).

Several studies have described the effects of behavioural modification therapy on patients with agitated or aggressive behaviour after ABI. These studies have usually been well-designed single-case studies with patients institutionalised at specialised departments for ABI patients with 
neuropsychiatric problems. Most of these studies showed positive results despite the fact that the subjects of the study had often suffered from the disturbing behaviour for years (see for example Alderman et al., 2002; Fluharty \& Glassman, 2001; Hegel \& Ferguson, 2000).

Although results from research studies have been positive, there appears to have been limited application of this type of intervention in routine clinical practice. One possible reason is that members of nursing staff caring for this patient group often lack the necessary skills, having not been sufficiently trained in the use of such methods. Nevertheless, the role of the nursing staff is essential in decreasing patients' challenging behaviour, given that the vast majority of incidents of aggression are immediately preceded by interactions between patients and nursing staff (Visscher et al., 2011).

In 1994, Cohn, Smyer, and Horgas already recognised the important role of the nursing staff for decreasing disruptive behaviour in geriatric patients. They developed the ABC method, a basic and simplified form of behavioural modification therapy especially designed for nursing staff. $\mathrm{ABC}$ focuses on the treatment of well-identified daily problem behaviour on a nursing ward. The acronym $A B C$ refers to the systematic identification and quantification of Antecedent events, target Behaviours, and Consequent events. The method provides nurses with a framework in which they learn that their own behaviour and other factors in the patient's environment can affect the emergence and persistence of challenging behaviour by patients. The principal idea is that situational factors trigger or influence the frequency and intensity of problem behaviours. The nurses learn to identify the triggers and to use this insight to develop a clear-cut intervention plan to decrease undesirable behaviour and increase desirable behaviour. A major difference with other therapy interventions is that members of nursing staff are fully responsible for the application of the $\mathrm{ABC}$ intervention. The nurses identify, observe and quantify the problem behaviour and design and evaluate the treatment plan. This makes it different from other behavioural interventions, where a psychologist may be primarily responsible for designing and evaluating a treatment.

Effects of the $\mathrm{ABC}$ method for patients with behavioural problems are unknown. The first research objective of our study therefore was to use a single-case experimental design to evaluate the effects of the ABC method on a patient with verbal aggressive behaviour after acquired brain injury. We hypothesised that the frequency and severity of the aggressive behaviour would decrease after use of the ABC method by the nursing staff.

The data in this study were analysed by means of both visual analysis and statistical analysis. The use and complementary value of these two methods for interpretation of the single-subject data were secondary objectives of this study and are discussed in this paper. 


\section{METHOD}

\section{Case history}

The patient was a 52-year-old woman who was diagnosed with olivo-pontocerebellar ataxia in 1992. In 1999, she was admitted to a specialised rehabilitation department for patients with $\mathrm{ABI}$ and neuropsychiatric problems because of an increase in physical problems (incontinence, muscle weakness, balance problems and deficits of fine motor skills) and cognitive and behavioural problems (agitation, apathy and delusional ideas). In 2004 she moved to a permanent-stay department also specialised for patients with neuropsychiatric problems after ABI.

The patient had been on paroxetine $(20 \mathrm{mg})$ for her agitation and irritability since 1999. In 2011, the dosage was increased to $30 \mathrm{mg}$. In 2007, depakine (300 mg three times per day) was added. Since 2009, oxazepam has been given when necessary $(10 \mathrm{mg}$, once or twice per day). Just before the start of the study, the patient started taking risperdal twice a day $(1 \mathrm{mg}$ and $0.5 \mathrm{mg}$ respectively) because of an increase in her agitation and irritability.

On assessment at the start of the study in 2011, the patient was wheelchairdependent. She was able to do some of her own ADL care but needed help with dressing, going to the toilet and showering. Her Mini Mental State Examination (MMSE) score was 14 (Folstein, Folstein \& McHugh, 1975).

The nursing staff reported that the patient regularly showed aggressive behaviour towards other patients. She became irritated with other patients during dinner, threw things about and threatened other patients with her fork and knife. During ADL care (i.e., going to the toilet, brushing teeth and washing/showering) she was often verbally aggressive towards the nursing staff. She yelled and cursed on almost all ADL care occasions and occasionally threatened to hit or pinch the nursing staff. This particular behaviour had already lasted for more than a year. Nurses reported that they experienced the behaviour as very disturbing.

\section{Study design}

The study used a single-case experimental AB design. The patient's target behaviour was evaluated over time, across baseline and intervention phases. Baseline target behaviour was assessed immediately before implementation of the $\mathrm{ABC}$ method on the ward. The point in time at which treatment began was randomly selected before the start of the study. The randomisation procedure determined that the baseline phase (phase A) should include nine measurement time points. The baseline behaviour was assessed twice per day on nine consecutive days. The two scores for each day were added up to form a total day score, which was used in the analysis. To evaluate any 
change in aggression, post-treatment (phase B) target behaviour was also assessed twice per day at thirty-six time points. These time points were spread over a post-treatment assessment period of nine weeks (four periods of nine consecutive days; treatment phase 1 started immediately after the implementation of the $\mathrm{ABC}$ method; phase 2 started three weeks after the implementation of the method; phase 3 started five weeks after implementation; and phase 4 started nine weeks after implementation). See Table 1 for a schematic representation of the measurement time points.

The patient in this study participated in a larger group study on the effects of the $\mathrm{ABC}$ method on patients with behavioural problems after ABI (a study that is still in progress). The group study also involves the use of several secondary outcome measures that were considered likely to be affected by the presence of aggression and by possible generalisation effects of the $\mathrm{ABC}$ method. Assessment took place twice during the baseline phase (to check for variance in the baseline data), viz. at six weeks before the implementation of the $\mathrm{ABC}$ method on the ward and immediately before implementation. Post-treatment assessment took place immediately after implementation of the method as well as nine weeks after its implementation. See Table 2 for a schematic representation of the measurement time points.

\section{Measures}

\section{Target behaviour}

At the start of the study, the patient frequently yelled, screamed and cursed and threatened nurses during ADL care (going to the toilet, brushing teeth, washing, showering) in the morning and in the evening. The goal of the study was to decrease the frequency and severity of the verbal aggressive behaviour. The main outcome measure for this goal was operationalised as verbal aggressive behaviour scored twice a day at each measurement time point by a nurse immediately after ADL care, on a scale from 0 to 4: $0=$ does not yell, scream or curse at all; $1=$ yells, screams or curses once; 2 $=$ yells, screams or curses several times; $3=$ yells, screams or curses a lot, threatens nurse once or several times; $4=$ continuous yelling, screaming, cursing or threatening. The two scores for each day were added up to a total day score, which was used in the analyses. Minimum score per day $=$ 0, maximum $=8$.

\section{Secondary outcome measures}

The Neuropsychiatric Inventory (NPI) was used to investigate the patient's behavioural and mood changes (Cummings, Mega, Gray, Rosenberg-Thompson, \& Gornbein, 1994). Frequency and severity scores are rated. Overall NPI 
TABLE 1

Schematic representation of the measurement time points for the target behaviour in the baseline and post-treatment phases

Baseline phase,

immediately before Treatment phase 1, immediately Treatment phase 2, three weeks Treatment phase 3, five weeks Treatment phase 4, nine weeks implementation after implementation

after implementation

after implementation

after implementation

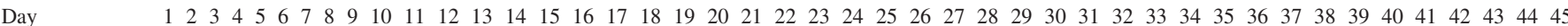

$\begin{array}{lllllllllllllllllllllllllllllllllllllllllllllllllllllllllll}\text { Target behaviour } & \mathrm{x} & \mathrm{x} & \mathrm{x} & \mathrm{x} & \mathrm{x} & \mathrm{x} & \mathrm{x} & \mathrm{x} & \mathrm{x} & \mathrm{x} & \mathrm{x} & \mathrm{x} & \mathrm{x} & \mathrm{x} & \mathrm{x} & \mathrm{x} & \mathrm{x} & \mathrm{x} & \mathrm{x} & \mathrm{x} & \mathrm{x} & \mathrm{x} & \mathrm{x} & \mathrm{x} & \mathrm{x} & \mathrm{x} & \mathrm{x} & \mathrm{x} & \mathrm{x} & \mathrm{x} & \mathrm{x} & \mathrm{x} & \mathrm{x} & \mathrm{x} & \mathrm{x} & \mathrm{x} & \mathrm{x} & \mathrm{x} & \mathrm{x} & \mathrm{x} & \mathrm{x} & \mathrm{x} & \mathrm{x} & \mathrm{x} & \mathrm{x}\end{array}$

\begin{tabular}{lllllllllllllllllllllllll}
$x$ & $\mathrm{x}$ & $\mathrm{x}$ & $\mathrm{x}$ & $\mathrm{x}$ & $\mathrm{x}$ & $\mathrm{x}$ & $\mathrm{x}$ & $\mathrm{x}$ & $\mathrm{x}$ & $\mathrm{x}$ & $\mathrm{x}$ & $\mathrm{x}$ & $\mathrm{x}$ & $\mathrm{x}$ & $\mathrm{x}$ & $\mathrm{x}$ & $\mathrm{x}$ & $\mathrm{x}$ & $\mathrm{x}$ & $\mathrm{x}$ & $\mathrm{x}$ & $\mathrm{x}$ & $\mathrm{x}$ & $\mathrm{x}$ \\
\hline
\end{tabular}

\section{TABLE 2}

Schematic representation of the measurement time points for the secondary outcome measures in the baseline and post-treatment phases

\begin{tabular}{|c|c|c|c|c|c|}
\hline & $\begin{array}{l}\text { Baseline phase (six } \\
\text { weeks before } \\
\text { implementation) }\end{array}$ & $\begin{array}{l}\text { Baseline phase } \\
\text { (immediately before } \\
\text { implementation) }\end{array}$ & $\begin{array}{l}\text { Treatment phase } 1 \text { (immediately } \\
\text { after implementation) }\end{array}$ & $\begin{array}{c}\text { Treatment phases } \\
2 \text { and } 3 \text { (three and } \\
\text { five weeks after } \\
\text { implementation) }\end{array}$ & $\begin{array}{l}\text { Treatment phase } 4 \text { (nine weeks } \\
\text { after implementation) }\end{array}$ \\
\hline $\begin{array}{l}\text { Day } \\
\text { Secondary }\end{array}$ & $\begin{array}{lllllllll}1 & 2 & 3 & 4 & 5 & 6 & 7 & 8 & 9\end{array}$ & $\begin{array}{lllllllll}1 & 2 & 3 & 4 & 5 & 6 & 7 & 8 & 9\end{array}$ & $\begin{array}{lllllllll}10 & 11 & 12 & 13 & 14 & 15 & 16 & 17 & 18\end{array}$ & & $\begin{array}{lllllllll}37 & 38 & 39 & 40 & 41 & 42 & 43 & 44 & 45\end{array}$ \\
\hline NPI & $\mathrm{X}$ & $\mathrm{X}$ & $\mathrm{X}$ & & $\mathrm{X}$ \\
\hline $\begin{array}{l}\text { SOAS-R } \\
\text { SDAS-11 }\end{array}$ & $\begin{array}{l}\text { X X X X X X X } \\
X\end{array}$ & $\begin{array}{l}\text { X X X X X X X X } \\
X\end{array}$ & $\begin{array}{llllllll}X & X & X & X & X & X & X \\
X & & & & & & & \end{array}$ & & $\begin{array}{llllllll}X & X & X & X & X & X & X \\
X & & & & & & & \end{array}$ \\
\hline ABS & X X X X X X X & X X X X X X X & $\begin{array}{llllllll}X & X & X & X & X & X & X\end{array}$ & & $\begin{array}{llllllll} & X & X & X & X & X & X\end{array}$ \\
\hline
\end{tabular}

NPI = Neuropsychiatric Inventory; SOAS-R = Staff Observation Aggression Scale-Revised; SDAS-11 = Social Dysfunction and Aggression Scale; ABS = Agitated Behaviour Scale. 
score ranges from 0 to 144 (higher score means more frequent and more severe problem behaviour).

The Staff Observation Aggression Scale-Revised (SOAS-R) was used to document the occurrence, nature and severity of aggression incidents (Nijman et al., 1999). The instrument is used to record the triggers that led to the aggressive behaviour, the means that were used by the patient during the incident, the target of the aggressive behaviour, consequences for victims, and the measures taken to control or stop the aggression. The overall severity score per incident ranges from 0 (least severe) to 22 (most severe aggression incident). In our study, the overall severity scores of all incidents that occurred on 7 consecutive days were added up and used as the total SOAS-R score.

The Social Dysfunction and Aggression Scale (SDAS-11) is an observation scale that was used to document the patient's aggressive behaviour (Wistedt et al., 1990). Total score ranges from 0 to 44 (higher scores represent more severe aggressive behaviour).

The Agitated Behaviour Scale (ABS) was used to measure the severity of agitation (Corrigan, 1989). Minimum total score is 14, maximum score is 64 (high scores represent severe agitation). In our study, a nurse completed the scale every day for seven consecutive days, at the end of an eight-hour shift. The mean score over seven days was used as the overall ABS score.

\section{Treatment method and procedure}

All nurses who worked with the patient were trained in working according to the ABC method developed by Cohn et al. (1994) and translated into Dutch by Hamer and Voesten (2001). The original method focused on dealing with behavioural problems in geriatric populations. For the purpose of the present study, we slightly adjusted the method for use in an ABI population, which meant that we used examples of problem behaviours and practice tasks that focused on younger patients and the kind of problem behaviours that are most common after ABI.

The ABC method rests on two main pillars. The first focuses on communication. Since most aggression incidents are preceded by interactions between patient and nurse, it is essential that communication between the two is optimal. The method provides nurses with information, advice and guidance for both verbal and non-verbal communication.

The second pillar of the method involves a simplified form of behaviour therapy. Key items in behaviour therapy are analysis and observation of the challenging behaviour. The $\mathrm{A}, \mathrm{B}$ and $\mathrm{C}$ can be regarded as the three main steps of the observation phase. For each step, all nurses jointly formulate questions that describe the antecedents (A), the challenging behaviour (B), 
and the consequences (C) of the behaviour. See Table 3 for an illustration of the three steps of observing behaviour.

The three steps of the observation phase automatically introduce 'three steps for changing behaviour': what kind of behaviour would we like to achieve, how can the antecedents be changed and how can the consequences be changed? These questions form the basis for a problem-oriented treatment plan. Thus, 'new desired' behaviour is formulated as a substitute for the undesirable challenging behaviour. Alternative antecedents or triggers that could encourage the desired behaviour are clearly described. And finally, the expected new and positive consequences are described. In most cases, very small changes that are implemented in a consistent manner are sufficient to accomplish a change in behaviour. Table 4 illustrates the three steps for changing behaviour.

All nurses attended three $\mathrm{ABC}$ training sessions for a total duration of 15 hours.

The first step in the treatment procedure was to identify the most important target behaviour for intervention. In the present study the nursing team chose the verbal aggressive behaviour during ADL care as the target behaviour. In the second step, the baseline phase measurements started. The third step involved the training programme, which took place after the baseline phase. The fourth step involved implementing the $\mathrm{ABC}$ method on the ward after the training programme, with the nursing staff working according to the ABC method. Finally, after implementation of the method on the ward, post-treatment assessments took place.

TABLE 3

Three steps in observing behaviour

Antecedent event (A): describe possible antecedent stimuli (triggers or situations).

What is going on in the patient him/herself?

What is happening in the patient's immediate environment?

Has anything changed recently?

Target Behaviour (B): describe the behaviour clearly.

What is the patient doing?

Where/when does it occur?

How long has this been going on?

How often does it occur and how serious is it?

For whom is it a problem?

Consequent events (C): describe the consequences.

How does the behaviour continue when it is ignored?

What is the response of the nurses and others to the patient's challenging behaviour?

What are the consequences for the patient? 
TABLE 4

Three steps for changing behaviour

\author{
New Antecedent events (A): \\ Which old antecedents can be altered? \\ Which new antecedents could encourage the desired behaviour? \\ Desired Behaviour (B): \\ What do we want the patient to do? \\ Is it possible to achieve this all at once? \\ Is the desired behaviour clearly described? \\ Is it attainable? \\ New Consequent events (C): \\ Can we avoid old consequences? \\ Which new consequences stimulate the new desired behaviour?
}

Table 5 shows the case-specific $\mathrm{ABC}$ for observation and $\mathrm{ABC}$ for change that was developed by the nursing staff and that was used in our study.

\title{
Data analysis
}

Verbal aggression during ADL care was plotted to allow for visual inspection (see Figure 1 below). Visualisation of the changes in level across phases was facilitated by superimposing horizontal reference lines representing the median scores for the baseline and treatment phases on the raw time series in the plot (Bulté \& Onghena, 2012).

A randomisation test was used to assess the statistical significance of the changes in level across phases. Applying a randomisation test first requires some aspect of the experimental design to be randomised (Eddington, 1980a, 1980b). In single-case studies, randomisation cannot be accomplished by randomly assigning entities to treatments. Instead, measurement occasions can be randomly assigned to treatments. In our case, the point in time at which treatment began was randomly selected before the start of the study. Theoretically, the treatment could be scheduled to start at any of forty-five observation time points in the trial. In this case, this was restricted so that both the baseline phase and treatment phase contained at least seven observations. Thus, treatment could start at any observation between eight and thirty-nine (i.e., not before or at the first seven observation occasions, and before the last seven observations). There were thus thirty-two possible starting points or permutations. Randomisation determined that treatment started after nine measurement time points, i.e., the baseline phase (phase A) included nine measurement time points.

Second, the randomisation test was used to derive a statistic from the observed data. In this case, it was expected that treatment would decrease 
TABLE 5

Patient-specific $A B C$ for observation and $A B C$ for change

\section{Observation}

Antecedent events (A):

"Patient has cognitive impairments. She may not understand what is going on, what is asked of her and she may be unable to do what is asked. She may be upset (The water is too hot? It is too early?). During the ADL care there is a nurse present who is talking to her and helping her get washed and dressed. Maybe she does not like the nurse talking to her during the shower".

\section{Target Behaviour (B):}

"Patient yells, screams and curses during ADL care. This happens in the bathroom, in the morning and in the evening. This has been going on for more than a year. It occurs every day and is a burden to the nurses, the patient herself and other patients".

Consequent events $(C)$ :

"When ignored, the patient's behaviour becomes worse and lasts longer, it becomes more difficult to calm her down. During the incidents, nurses try to distract her, try to show consideration, to be positive, and to shower her quickly. As a consequence the patient becomes more upset, and yells, screams and curses even more".

\section{Change}

New antecedent events (A):

"Try to help her understand what is going on by explicitly explaining what is happening (I am now going to put shampoo on your hair, I am now going to wash your hair). Try to prevent her getting upset by checking the temperature of the water. Less talking, but give clear instructions. Have breakfast first, then shower at a later moment".

\section{Desired Behaviour (B):}

"The goal is to decrease the frequency and severity of the challenging behaviour; the patient is allowed to yell, scream or curse a few times during the ADL care, but the patient will no longer threaten the nurses or show continuous screaming, yelling or cursing. It is not expected that this can be achieved at once".

New Consequent events (C):

"Most of the time the patient is calm and cooperates with the nurse. Now and then the patient may scream, yell or curse but she does not threaten the nurses".

the frequency of the aggressive behaviour. A $t$-statistic was used to compare differences between phase scores. The statistic was used for all the possible permutations of the data generated during the randomisation process: $t$-statistics were calculated as if data had been collected for each of the thirtytwo permutations. The probability associated with the observed statistic was computed by dividing the number of computed statistics that were as large as or larger than the statistic for the observed data set by the total number of possible permutations (Perdices \& Tate, 2009).

Effect size for the treatment was also calculated by using Nonoverlap of All Pairs (NAP). Parker and Vannest (2009) recommend the use of this index for calculating effect sizes in single-case research given that the data 
show no trend. The NAP is especially useful for data with high variability since the NAP takes all possible baseline and intervention phase measurements into account.

Finally, pre-, post- and follow-up assessment scores for the secondary outcome measures derived from the larger group study were described.

\section{RESULTS}

\section{Target behaviour}

\section{Verbal aggression during $A D L$ care}

Figure 1 shows the baseline and intervention measurement time points for the target behaviour.

Due to the high variance in the data it was difficult to judge treatment effects based on visual analysis of the raw data alone. Visual analysis showed that the target behaviour was still present after implementation of the method and that on some days the behaviour was even judged to be more severe than at baseline. Adding median reference lines showed a decline in severity score after treatment: the median verbal aggression score per day at baseline was 3.00, falling to 2.50 after implementation of the method on the ward (lowest possible score per day was 0 , highest was 8).

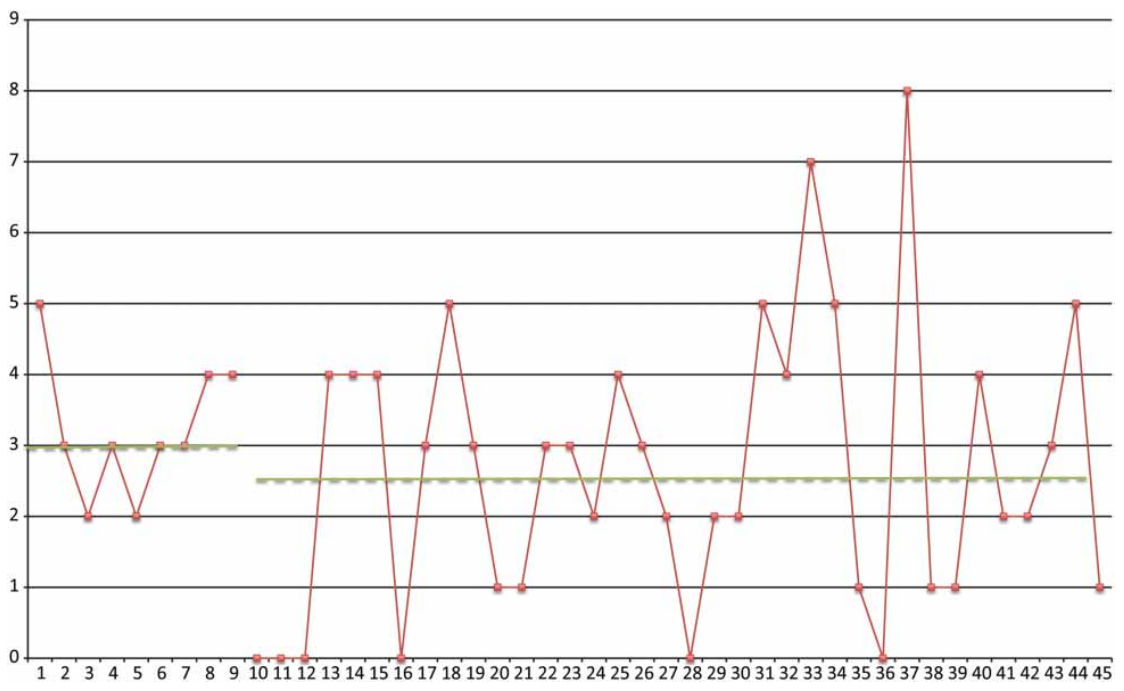

Figure 1. Verbal aggression during ADL as rated by nurses. Days 1 to 9 form the baseline phase (phase A), days 10 to 45 the treatment phase (phase B). 


\section{TABLE 6}

Secondary outcome measures at baseline (six weeks before implementation of the method and immediately before implementation) and after treatment (immediately after implementation and nine weeks after implementation)

\begin{tabular}{lcccc}
\hline & $\begin{array}{c}\text { Baseline phase } \\
\text { (six weeks } \\
\text { before } \\
\text { implementation } \\
\text { of the method) }\end{array}$ & $\begin{array}{c}\text { Baseline phase } \\
\text { (immediately } \\
\text { before } \\
\text { implementation } \\
\text { of the method) }\end{array}$ & $\begin{array}{c}\text { Treatment phase } \\
\text { 1 (immediately } \\
\text { after } \\
\text { implementation } \\
\text { of the method) }\end{array}$ & $\begin{array}{c}\text { Treatment phase } \\
\text { (nine weeks } \\
\text { after } \\
\text { implementation } \\
\text { of the method) }\end{array}$ \\
\hline $\begin{array}{c}\text { NPI }(\min =0 ; \\
\max =144)\end{array}$ & 67 & 43 & 50 & 48 \\
$\begin{array}{c}\text { SOAS-R }(\min =0 ; \\
\max =154)\end{array}$ & 51 & 0 & 15 & 28 \\
$\begin{array}{c}\text { SDAS-11 }(\min =0 ; \\
\max =44)\end{array}$ & 21 & 20 & 18 & 22 \\
$\begin{array}{c}\text { ABS }(\min =14 ; \\
\max =64)\end{array}$ & 22.7 & 19 & 18.7 & 25.6 \\
\hline
\end{tabular}

NPI = Neuropsychiatric Inventory; SOAS-R = Staff Observation Aggression Scale-Revised; SDAS-11 $=$ Social Dysfunction and Aggression Scale; ABS $=$ Agitated Behaviour Scale.

Statistical analysis showed a statistically significant difference between the baseline and intervention phases $(t=.58, p=.03)$ : on average, the patient showed less severe verbal aggressive behaviour after implementation of the $\mathrm{ABC}$ method. The intervention effect size (NAP) was weak $(E S=.62$; Parker \& Vannest, 2009).

\section{Secondary measures}

The patient's scores on the secondary outcome measures are presented in Table 6.

The results show that the scores in both baseline phases and both treatment phases varied greatly. Although these secondary outcome measures were likely to be affected by a decrease in the patient's target behaviour, the results for these measures show no clear generalisation effects of the implementation of the method by the nursing staff.

\section{DISCUSSION}

\section{Effects of the ABC method}

Statistical analysis of the data demonstrated that implementation of the $\mathrm{ABC}$ method successfully decreased the frequency and severity of the target behaviour: the intervention had a (weak but) specific effect on verbal aggressive 
behaviour during ADL care. The results are in line with results from other studies on the effects of behavioural modification therapy in patients with agitated or aggressive behaviour after ABI (see for example Alderman et al., 2002; Fluharty \& Glassman, 2001; Hegel \& Ferguson, 2000).

Although the statistical data analysis showed positive and statistically significant treatment results in terms of a decrease in the frequency and severity of the patient's verbal aggressive behaviour, visual analysis also showed that the behaviour was still present after implementation of the method and seemed to have become more unpredictable. Although the behaviour seemed to have disappeared in the first three days after implementation of the treatment, the treatment phase results also show that on some days after implementation, nurses judged the behaviour to be more severe than at baseline.

This suggests that further and more detailed analysis of the data is required. What happened on the days when the verbal aggressive behaviour was absent? Were the nurses more consistent in working according to the $\mathrm{ABC}$ method for behaviour change in the first few days after implementation? Who was taking care of the patient on these days? On the other days, was the target behaviour present especially during the morning ADL care or in the evenings? And so on.

Some limitations of this study also need to be acknowledged. First, one could argue that the patient's problem behaviour could have been caused by many other factors that were not taken into account (such as premorbid characteristics of the patient, concurrent mental health issues, etc.). This may have influenced the outcome of the intervention. However, the ABC method does not aim to capture the complexity of all issues influencing behaviour. Instead, it aims at 'small' and concrete identifiable problem behaviour, and at triggers that can easily be changed by the nursing staff. When using the $\mathrm{ABC}$ method, the nursing team is in charge of analysing the problem behaviour and coming up with an intervention plan, without the help or input of a psychologist or psychiatrist. The aim of our paper was to investigate whether such a 'simple' method could be effective in diminishing problem behaviour after acquired brain injury.

Second, no control behaviour was assessed that was not subjected to the $\mathrm{ABC}$ method, and no withdrawal phase was used to study whether the aggressive behaviour would return when the $\mathrm{ABC}$ method was no longer used by the nursing team.

Third, it is difficult to draw conclusions about the generalisability of the effects of the method to other measures of aggressive behaviour and to other patients. Only one target behaviour was assessed, the baseline and treatment phase scores on the secondary outcome measures were variable and therefore difficult to interpret, and effects of the method were studied in one patient only.

Fourth, different nurses assessed the target behaviour at the different measurement time points. This may have biased the results, as one nurse 
may experience the verbal aggressive behaviour as more severe than another nurse. Nothing is known about the sensitivity and inter-rater reliability of this measurement method. Ideally one would use only standardised measures for evaluating intervention effects. However, when using the ABC method, one first analyses the very specific problem behaviour that one wants to cope with. And then one chooses a measurement that exactly fits that specific problem behaviour and the goals the nursing team wants to achieve. Existing structured and validated measures are often not useful.

Fifth, verbal aggression during different ADL activities was measured: on some days verbal aggression during going to the toilet and during washing was reported, on other days ratings concerned verbal aggression during showering. The variability in ratings may have been related to the varying demands between the two different types of activities. Measurement error would have been better controlled if only one ADL event had been reported.

Lastly, as said, the nurses were in charge of working according to the $\mathrm{ABC}$ method. It is very likely that they needed more time to get used to taking that responsibility and using the method consistently. We expect that a longer follow-up period with post-treatment assessments at six months or at a year after implementation of the method on the ward may show larger treatment effects.

\section{Value of visual and statistical analysis for interpreting single- subject data}

Techniques for analysis and interpretation of single-subject data fall into two main categories: visual analysis and statistical analysis (Perdices \& Tate, 2009). Raw data are usually represented graphically and readily lend themselves to visual analysis. An advantage of visual analysis may be that small treatment effects will be ignored and only very large, obvious effectswhich are also most likely to be clinically relevant-will be detected (Bulté \& Onghena, 2012). Disadvantages of visual analysis may be that it leaves room for subjectivity: no formal criteria or decision rules are used and inter-rater agreement can be low (Jones, Weinrot, \& Vaught, 1978; Ottenbacher, 1993). Also, consistent but relatively weak effects are easily overlooked (Bulté \& Onghena, 2012).

Statistical tests use precisely defined criteria for significance to determine if the treatment effect is reliable. This is also valuable if the baseline level is not stable. In addition, statistical tests use an explicit set of operational rules and replicable methods that control for type I errors (i.e., incorrect rejection of a true null hypothesis; Perdices \& Tate, 2009). The results from the present study illustrate this. The high variance in the data made it difficult to judge treatment effects based on visual analysis of the raw data alone. The randomisation test, however, showed a statistically significant treatment effect. 
Statistical significance, however, does not necessarily mean that treatment has had a clinically significant impact. The data in the present study showed that-although there was a statistically significant treatment effect- target behaviour was still present after implementation of the method. What is more, the target behaviour seemed to have become more unpredictable after treatment. The target behaviour was absent on some days, but on other days it was judged to be more severe than before baseline. The results from this study illustrate the need to employ visual inspection to inform the interpretation of the statistical analysis (Perdices \& Tate, 2009).

\section{CONCLUSION}

The $\mathrm{ABC}$ method for use by nurses is a promising tool for decreasing problem behaviour in patients with ABI. An important characteristic of this method is that the nursing staff are in charge of the intervention; nurses are given more responsibility and independence in dealing with problem behaviour. Although target behaviour was still present after implementation of the method in our study, we believe it is worth investing in future studies of this method. Finally, the results from this study show that it is desirable to employ visual inspection to inform the interpretation of the statistical analysis when it comes to interpreting single-subject data. Both visual inspection and statistical analysis are needed in order to judge whether treatment is effective and whether the effects lead to clinically desirable results.

\section{REFERENCES}

Alderman, N. (2007). Prevalence, characteristics and causes of aggressive behaviour observed within neurobehavioural rehabilitation services: Predictors and implications for management. Brain Injury, 9, 891-911.

Alderman, N., Knight, C., \& Henman, C. (2002). Aggressive behavior observed within a neurobehavioral rehabilitation service: Utility of the OAS-MNR in clinical audit and applied research. Brain Injury, 16, 469-489.

Azouvi, P., Jokic, C., Attal, N., Deny, P., \& Bussel, B. (1999). Carbamazepine in agitation and aggressive behavior following severe closed-head injury: Results of an open trial. Brain Injury, 13, 797-804.

Baguley, I. J., Cooper, J., \& Felmingham, K. (2006). Aggressive behavior following traumatic brain injury. How common is common?. Journal of Head Trauma Rehabilitation, 21, $45-56$.

Bulté, I., \& Onghena, P. (2012). When the truth hits you between the eyes: A software tool for the visual analysis of single-case experimental data. European Journal of Research Methods for the Behavioral and Social Sciences, 8(3), 104-114.

Ciurli, P., Formisano, R., Bivona, U., Cantagallo, A., \& Angelelli, P. (2011). Neuropsychiatric disorders in persons with severe traumatic brain injury: Prevalence, phenomenology, and relationship with demographic, clinical, and functional features. Journal of Head Trauma Rehabilitation, 26, 116-126. 
Cohn, M. D., Smyer, M. A., \& Horgas, A. L. (1994). The A-B-Cs of behavior change: Skills for working with behavior problems in nursing homes. State College, PA: Venture.

Corrigan, J. D. (1989). Development of a scale for assessment of agitation following traumatic brain injury. Journal of Clinical and Experimental Neuropsychology, 11, 261-277.

Cummings, J. L., Mega, M., Gray, K., Rosenberg-Thompson, S., \& Gornbein, J. (1994). The Neuropsychiatric Inventory: Comprehensive assessment of psychopathology in dementia. Neurology, 44, 2308-2314.

Eddington, E. S. (1980a). Random assignments and statistical tests for one-subject experiments. Behavioral Assessment, 2, 19-28.

Eddington, E. S. (1980b). Variability of randomization tests for one-subject experiments. Journal of Educational Statistics, 5, 235-251.

Fluharty, G., \& Glassman, N. (2001). Use of antecedent control to improve the outcome of rehabilitation for a client with frontal lobe injury and intolerance for auditory and tactile stimuli. Brain Injury, 15, 995-1002.

Folstein, M. F., Folstein, S. E., \& McHugh, P. R. (1975). Mini-Mental State: A practical method for grading the cognitive state of patient for the clinician. Journal of Psychiatry, 12, 189-198.

Hamer, T., \& Voesten, F. (2001, February). Gedragsverandering? Een ABC-tje! Een cursus voor ziekenverzorgenden [Changing behaviour? An $\mathrm{ABC}$ ! A training programme for nursing staff]. Denkbeeld, pp. 20-24.

Hegel, M. T., \& Ferguson, R. J. (2000). Differential reinforcement of other behavior (DRO) to reduce aggressive behavior following traumatic brain injury. Behavior Modification, 24, 94-101.

Johnson, R., \& Balleny, H. (1996). Behavior problems after brain injury: Incidence and need for treatment. Clinical Rehabilitation, 10, 173-181.

Jones, R. R., Weinrot, R., \& Vaught, R. S. (1978). Effects of serial dependence on the agreement between visual and statistical inferences. Journal of Applied Behavioral Analysis, 11, $277-283$.

Kant, R., Smith-Seemiller, L., \& Zeiler, D. (1998). Treatment of aggression and irritability after head injury. Brain Injury, 12, 661-666.

Nijman, H. L. I., Muris, P., Merkelbach, H., Palmstierna, T., Wistedt, B., Vos, A. M., \& Van Rixtel, A. (1999). The Staff Observation Aggression Scale-Revised (SOAS-R). Aggressive Behavior, 25, 197-209.

Ottenbacher, K. J. (1993). Interrater agreement of visual analysis in single-subject designs: Quantitative review and analysis. American Journal of Mental Retardation, 98, 135-142.

Parker, I. R., \& Vannest, K. (2009). An improved effect size for single-case research: Nonoverlap of all pairs. Behavior Therapy, 40, 357-367.

Perdices, M., \& Tate, R. L. (2009). Single-subject designs as a tool for evidence-based clinical practice: Are they unrecognised and undervalued? Neuropsychological Rehabilitation, 19, 904-927.

Visscher, A. J. M., Van Meijel, B., Stolker, J. J., Wiersma, J., \& Nijman, H. (2011). Aggressive behaviour of inpatients with acquired brain injury. Journal of Clinical Nursing, 20, 3414-3422.

Wistedt, B., Rasmussen, A., Pedersen, L., Malm, U., Traskman-Bendz, L., Wakelin, J., \& Bech, P. (1990). The development of an observerscale for measuring social dysfunction and aggression. Pharmacopsychiatry, 23, 249-252.

Ylvisaker, M., Turkstra, L., Coehlo, C., Yorkston, K., Kennedy, M., Sohlberg, M. M., \& Avery, J. (2007). Behavioural interventions for children and adults with behavioural disorders after TBI: A systematic review of the evidence. Brain Injury, 21, 769-805. 